\title{
Analysis for Gold
}

\section{A REVIEW OF METHODS}

\author{
Roland S. Young \\ Consultant, Victoria, B.C., Canada
}

Fire assay is one of the earliest methods of quantitative chemical analysis and in most circumstances it has remained the most accurate for the determination of gold. With the development of modern laboratory techniques and instrumentation, however, alternative methods have become available which may offer the advantage of rapid determination, although with some sacrifice in precision.

Gold, by reason of its occurrence in the metallic state, was probably one of the first metals known to man. Its brilliant colour, high specific gravity, resistance to corrosion and excellent malleability have since given it a privileged place among metals. For several centuries in the medieval period, alchemists endeavoured to transmute base metals into gold; their efforts, of course, were unsuccessful but resulted in early knowledge of the chemical behaviour of gold and its compounds. From the beginning of quantitative chemical analysis, the high value of gold dictated careful sampling and a degree of analytical accuracy far greater than that required for all other metals except those of the platinum group.

During the long association of man with gold, the determination of the latter in ores and metallurgical products has been generally carried out by fire assay. In this technique of analytical chemistry, the sample is mixed with appropriate fluxes and litharge in a crucible, and is melted in a furnace. Gold, having a weak affinity for non-metallic elements at high temperature, but a very strong affinity for the molten lead formed by reduction of litharge, is collected in a lead button. When the latter is heated under oxidizing conditions in a porous vessel called a cupel, the lead is rapidly oxidized to $\mathrm{PbO}$ which is 98.5 per cent absorbed by the cupel and 1.5 per cent volatilized, leaving the gold, and silver if present, in the form of a bead. Subsequent treatment with dilute nitric acid, termed 'parting', dissolves the silver, and the residue of gold is then weighed on a special type of balance which is sensitive to at least $0.005 \mathrm{mg}$.

Though very important, fire assaying is not the only method used in the determination of gold. For many gold-bearing materials, gravimetric, volumetric and colorimetric procedures, or the techniques of atomic absorption, optical spectrography and X-ray fluorescence are employed.

\section{Sample Preparation}

Samples of ores, concentrates, mattes, slags, flue dusts, refinery residues and similar gold-containing materials are usually pulverized to pass a 100-mesh sieve, which has a nominal opening $0.15 \mathrm{~mm}$ in diameter. Blister and anode copper, lead and other bullions may be sampled in the liquid state by shotting or dipping, or in the solid condition by drilling or sawing.

Gold determinations are frequently required in liquids such as solutions in plating works or in gold reduction plants. These usually do not involve more than delivery directly to the laboratory of samples of appropriate volume.

When gold is in the form of coinage, jewellery or decoration on glass or porcelain, a difficult compromise must often be made between the quantity of material required for a representative sample and the amount permissible on economic grounds. The great malleability of gold may make the preparation of some samples a little difficult, the metal tending to smear on pulverizing equipment rather than reduce in size to powder. One remedy is to be content with coarser material and to take a large sample for analysis. The gold is dissolved from this sample, the solution is made up to volume in a large flask and a suitable aliquot is taken for analysis.

\section{Detection}

Gold may be detected by optical emission spectrography, generally with the lines 242.8 and $267.6 \mathrm{~nm}$.

A rapid 'Purple of Cassius' colour test is sometimes used to detect the presence and semi-quantitatively determine the concentration of gold in tailing solutions. A large sample (1 litre) of the latter is shaken with a small quantity of sodium cyanide solution, zinc dust and lead acetate solution; the liquid is decanted and the precipitate is treated with aqua regia, cooled, 
and a few drops of a stannous chloride solution are added. A tint varying from yellow to purple is produced by solutions containing from 0.03 to $0.3 \mathrm{ppm}$ of gold respectively $(1,2)$.

\section{Dissolution}

Gold is not dissolved in single acids, but is readily soluble in aqua regia. Because most base metals are soluble in nitric acid, hydrochloric acid or sulphuric acid, treatment of many samples with one of these mineral acids serves to isolate or concentrate gold in a small residue.

Gold is also dissolved by the alkali cyanides in the presence of oxygen. Although nearly all the world's gold output is extracted in this way, the reaction is only occasionally used in chemical analysis.

If a residue remains after aqua regia treatment, it must be brought into solution by the action of hydrofluoric acid, or by fusion with sodium carbonate or other fluxes.

Gold is precipitated completely as sulphide when hydrogen sulphide is passed through its solutions in

\section{Separation}

0.2 to $3 \mathrm{~N}$ hydrochloric acid or 0.5 to $36 \mathrm{~N}$ sulphuric acid. The twenty other elements of the hydrogen sulphide group behave similarly. A differentiation of most members of the hydrogen sulphide group can be made by their solubility, or insolubility, in ammonium polysulphide solution; gold, however, is partially soluble and cannot therefore be separated from other members by this reagent.

When sulphur dioxide is passed into a hydrochloric acid solution of gold, the latter is precipitated. Only selenium, tellurium and a trace of lead accompany gold and these are dissolved on treatment of the precipitate with nitric acid, leaving the gold as a residue $(3,4,5)$.

Many alternative methods of separating gold from other elements are discussed in detail in reference books and articles. They include procedures based on the use of ether extraction (6), dithizone $(5,6,7)$, methyl isobutyl ketone extraction (8 to 13), ion exchange $(14,15,16)$, cupferron (6), 1-nitroso-2naphthol (6), sodium nitrite $(3,4,5)$, zinc or magnesium (6), oxalic acid $(4,5,17)$, hydroquinone (14, 18), tellurium (19) and trimethylphenylammonium iodide (20).

\section{The Determination of Gold}

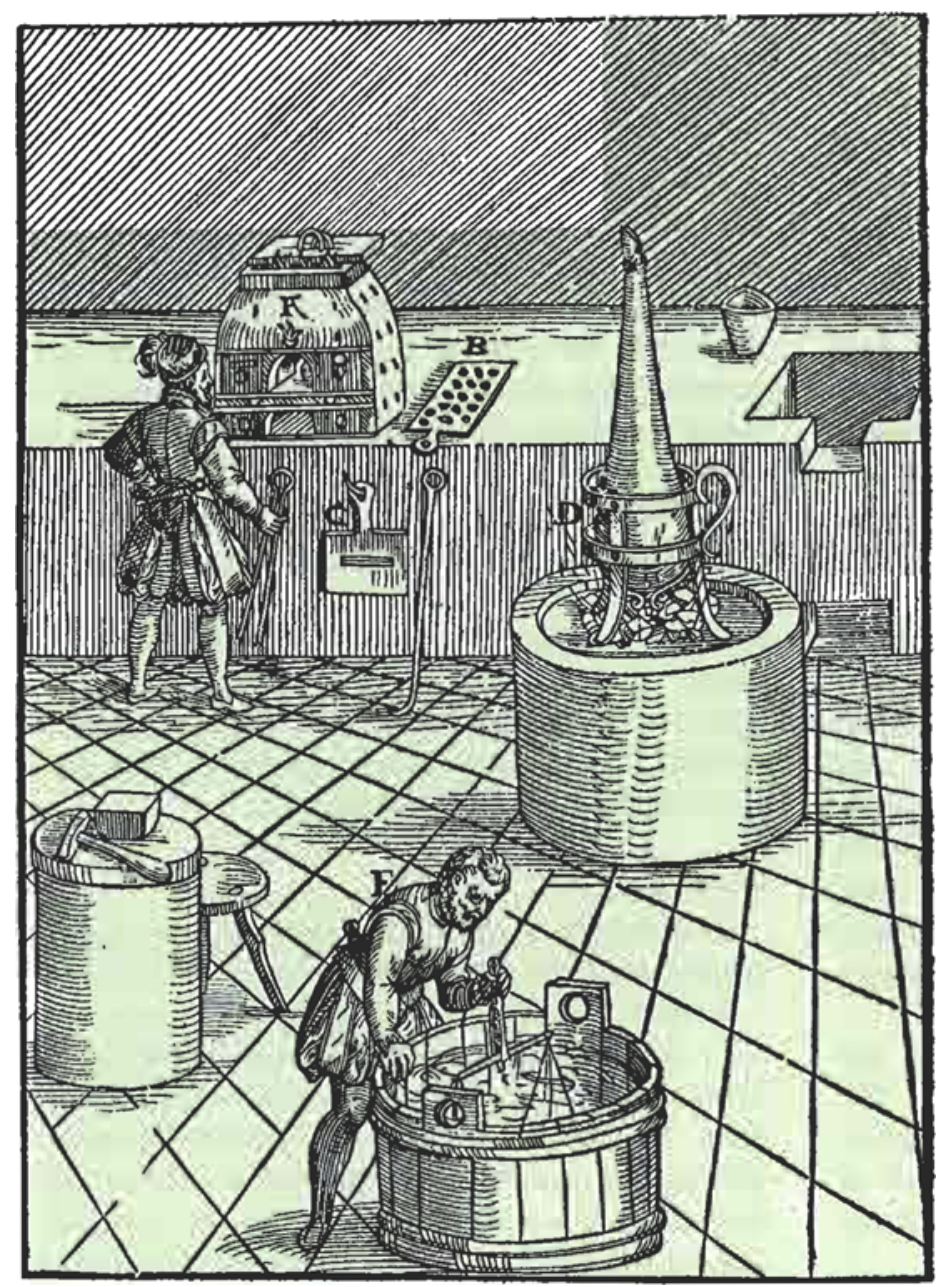

The application of the fire assay technique to various types of materials will be described, after which alternative methods will be discussed.

Fire Assay of Ores and Concentrates

A mixture of the pulverized sample with about three parts of a flux is placed in an assay crucible and heated in a furnace until the product is molten and has attained a temperature of 900 to $1100^{\circ} \mathrm{C}$,

Cupelling, parting and performing a density assay of gold in a medieval laboratory. This illustration is reproduced from Lazarus Ercker's 'Treatise on Ores and Assaying', published in Prague in $\mathbf{1 5 7 4}$ 
A battery of electric cupellation furnaces at Rand Refinery in Germiston. Routine fire assays at the Refinery are made on a twin-stream duplicate system in two entirely separate assay offices. The temperature in the furnaces shown herc is $1040^{\circ} \mathrm{C}$ and cupellation in magnesia cupels takes 25 minutes

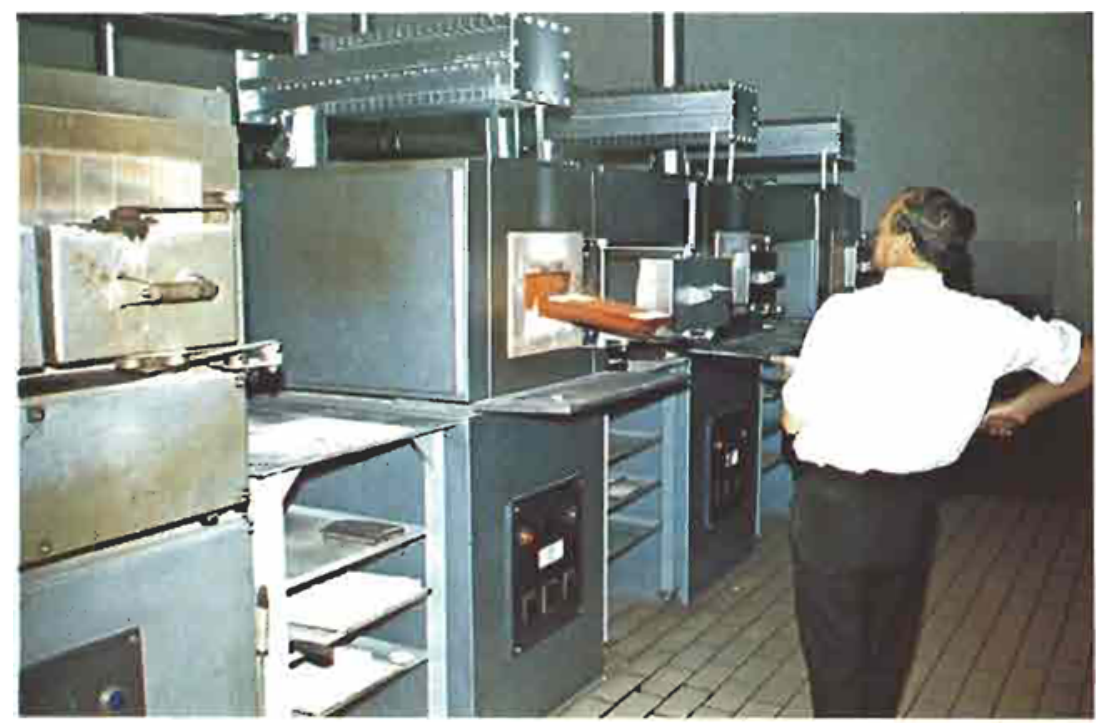

which usually requires 25 to 40 minutes. One of the ingredients of the flux is a lead compound which is reduced by other constituents of the flux or sample to metallic lead. The latter collects all the gold, together with silver, platinum group metals and small quantities of certain base metals, and falls to the bottom of the crucible to form a lead button. The gangue of the ore must be converted by fluxes into a slag sufficiently fluid so that all particles of lead may fall readily through the molten mass. The choice of a suitable flux depends on the nature of the ore; the subject is fully covered in reference books $(1,3,5,14,18,21,22)$.

If the sulphur content of the material exceeds 2 per cent, the sample must be roasted before mixing with the flux. It is placed in a flat fireclay dish and calcined in an open furnace, applying the heat gradually to about $500^{\circ} \mathrm{C}$ and then increasing it to $750^{\circ} \mathrm{C}$ until no more fumes are evolved. If appreciable quantities of arsenic or antimony are present, a little fine charcoal is added at this stage and the roasting is repeated. If chlorides are present, roasting must not be practised - most of the gold is volatilized from a sample containing 10 per cent sodium chloride if it is roasted at $750^{\circ} \mathrm{C}$ for 30 minutes.

The precision of balances has made fire assay a very accurate method for the quantitative determination of gold. The two cornets shown here next to a match, are what remains of flattened and coiled gold-silver beads after the final operation of parting in nitric acid. The smaller cornet, with a mass of $0.005312 \mathrm{~g}$, might result from sanpling of a piece of jewellery for assay prior to hallmarking. Such sampling is usually inade with a sharp hand-tool by scraping small shavings from a part of the object which is not nornally visible. The larger cornet, witl a mass of $0.37529 \mathrm{~g}$, is representative of an assay performed on a gold alloy semi-product such as tubing, slıeet or wire

Photograph by courtesy of the South African Bureau of Standards, Pretoria
At the end of the fusion, the sample is poured into a cast iron mould, allowed to cool, and the lead button is hammered free of slag. The button is then placed in a cupel and cupellation is carried out at approximately 850 to $900^{\circ} \mathrm{C}$; if gold alone is to be determined, a temperature of 950 to $1000^{\circ} \mathrm{C}$ may be used. When only the noble metal bead is left in the cupel, the latter is removed from the muffle and is allowed to cool. The bead is removed from the cupel with forceps, flattened carefully on an anvil to remove any adhering cupel particles and weighed on the assay balance as gold + silver.

Silver is removed by parting the bead in a small porcelain cup, first with dilute $(1 / 6)$ nitric acid and then with more concentrated $(1 / 1)$ nitric acid. After 
washing three times by decantation with hot water, drying and annealing by heating for a few seconds at a bright red heat, the gold bead is weighed. The difference in masses represents silver.

If there is less than three times as much silver as gold in the bead, the silver does not dissolve readily and parting is difficult. In this case, a suitable addition of pure silver foil must be made after weighing the goldsilver bead, or preferably before the original cupelling.

When the sample contains metals of the platinum group, platinum, palladium and osmium are dissolved in parting; iridium, rhodium and ruthenium remain as a residue with the gold. In this case, the content of silver in the bead should be ten times that of gold + platinum group metals. If iridium, rhodium and ruthenium are present in more than trace amounts, the bead must be dissolved in aqua regia from which the gold is precipitated with sulphur dioxide and then weighed.

Where the silver content of an ore is low and uniform, beads derived from routine mine samples are often not parted; an allowance is made for the silver which the ore is known to contain. This is the practice followed, for instance, in the vast and highly efficient gold mining industry of South Africa.

Parting may also be carried out in hot, slightly diluted sulphuric acid. Palladium and some of the ruthenium dissolve with the silver, leaving platinum, iridium, rhodium and osmium with the gold residue. For sulphuric acid parting in the presence of platinum group metals, the bead should have the approximate composition: platinum group metals/gold/silver equal to $1 / 10 / 33$ by weight.
For concentrates and similar materials rich in base metals, it is good practice to separate most of the latter by wet treatment after roasting. The calcine is treated in a large beaker with $1 / 1$ sulphuric acid and the mixture is evaporated to fuming point. After cooling, diluting with water, boiling, cooling and adding a solution of sodium chloride, the sample is allowed to stand overnight. Filtration followed by washing with hot water gives a precipitate of gold, silver chloride and insoluble material; the inside of the beaker is wiped carefully with filter paper which is added to the precipitate. The latter, together with the paper, is then transferred to an assay crucible, dried, mixed with flux and the determination is continued as described earlier.

\section{Fire Assay of Blister Copper and Refinery Slimes}

A significant portion of the world's gold output is obtained as a by-product of the base metal industries. Thus, fire assay of copper or other base metal-rich samples is fiequently required. Treatment of such samples with sulphuric acid in the presence of a little mercuric sulphate solution dissolves base metals; addition of sodium chloride to precipitate silver, followed by filtration, gives a small residue of gold, silver, platinum group metals and insoluble material. This is wrapped in a lead foil and placed in a scorifier, the paper is burned off, test lead, borax and silica are added, and the sample is scorified until base metals are transferred to the slag and a lead button is left. Cupellation, parting and weighing the bead are then carried out in the normal manner $(5,23)$.

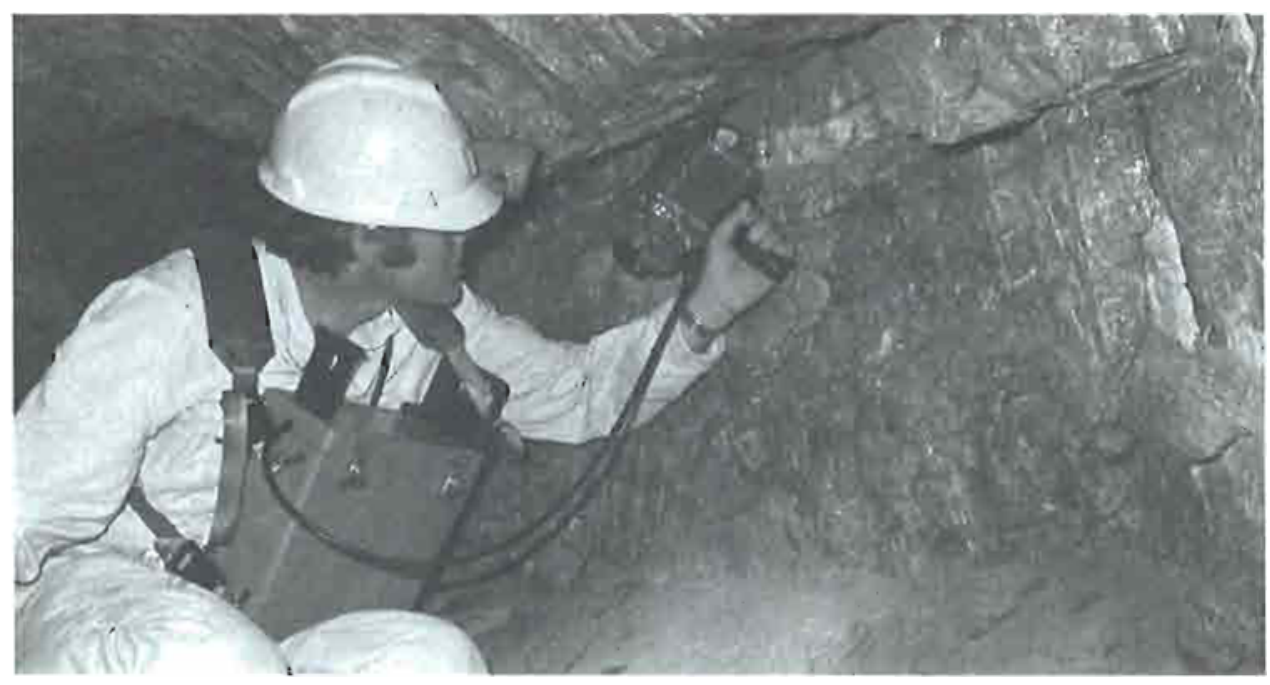

Prototypes of the portable gold analyzer, which was developed by the Research Organization of the Chamber of Mines of Sonth Afriea, have been extensively tested underground. This sampler is measuring the gold content of a stope lace with the liand-held probe of the instrumemt. The probe is permunently connected to the chest pack which coniains electronic circuitry, including a memory, controls and rechargeable batteries. Upon completion of a series of measurements, which may take np to 6 hours and cover up $10250 \mathrm{~m}$ of lace, the chest pack is connected to a control module for processing and print-out of the data stored in the nemory and for battery recharging 


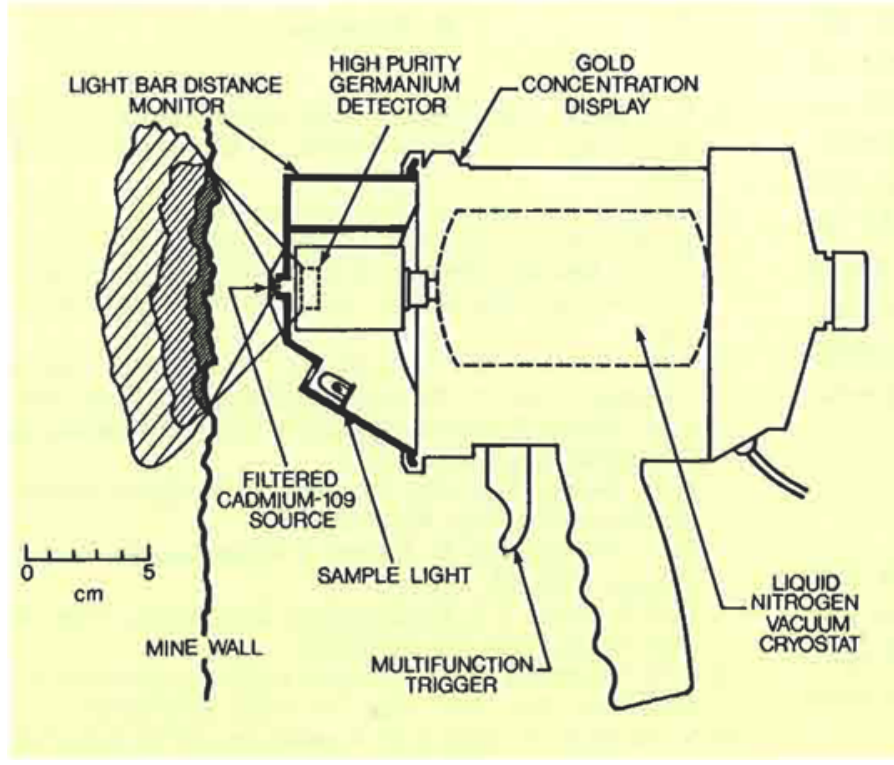

The hand-held probe of the portable gold analyzer consists of a filtered cadmium-109 source of gamma-rays which is protected by a heavy metal shield with a shutter. Immediately behind the source is a germanium detector, mounted in a small spill-proof container of liquid nitrogen whieh has to be refilled after each shift. Below the detector is a light that illuminates the area being sampled. There are two displays on top of the probe, one indicating the effective distance from the rock face and the other the result of the measurement of the gold content of the rock. Actuating the trigger both opens the shutter to start a measurement and stores the result at the end of a measurement. The gamma-rays excite the gold at an average depth of $2.5 \mathrm{~cm}$ into the rock. The probe is used to scan the face from a distance of about $5 \mathrm{~cm}$ and the width scanned is about $8 \mathrm{~cm}$. The unit is designed for underground use and is of robust construction, but its mass is only $1.2 \mathrm{~kg}$
Fire Assay for Determining Gold in Cyanide Solutions

A satisfactory procedure for the determination of gold in various cyanide solutions is based on the fact that gold and silver are quantitatively precipitated from such solutions when copper sulphate, sodium sulphite and sulphuric acid are added to them. The precipitate is filtered, placed in a scorifier and dried, lead and borax are added and scorification, cupellation and parting are carried out as usual $(1,2,5)$.

\section{Gravimetric Determination}

A popular and very satisfactory method for determining intermediate and larger quantities of gold depends on the fact that sulphur dioxide will reduce gold in hydrochloric acid solution to the metal. Only selenium, tellurium and traces of lead will be found with the gold precipitate, and these can be removed by treatment with nitric acid. A re-solution of the final gold precipitate in aqua regia and a second treatment with sulphur dioxide are advisable, especially if the sample contains platinum group metals $(3,4,5$, $14,18,24)$.

Alternative reliable gravimetric procedures for gold utilize sodium nitrite $(5,14,18)$, oxalic acid $(5,14$, $17)$, hydroquinone $(14,18)$ and other reagents $(20)$.

\section{Volumetric Determination}

Various volumetric procedures for gold have been proposed, but nearly all have restricted application $(14,18)$.

\section{Colorimetric and Spectrophotometric Determination}

A large number of colorimetric methods for determining small quantities of gold has been published. Some methods are characterized by fairly wide application and satisfactory reliability, but many have been developed for a specialized purpose and are unsuitable for general work. Among the important colorimetric and spectrophotometric procedures are those utilizing o-tolidine $(10,14,18,25)$, bromaurate $(14,25,26)$, rhodamine B $(14,25)$, rhodanine $(25$, $27)$, dithizone $(7,25,28)$ and trioctylamine (29).

\section{Atomic Absorption Spectrophotometry}

Atomic absorption is a valuable technique for the determination of small quantities of gold. An airacetylene or other suitable flame is used and the most sensitive line is $242.8 \mathrm{~nm}$; a less absorbing line at $267.6 \mathrm{~nm}$ is sometimes also employed. The presence of certain elements exerts a considerable depression or enhancement of the gold absorption and it is advisable to have the standards roughly similar in composition to the test solutions. Alternatively, the gold can be isolated or concentrated by solvent extraction, ion exchange or fire assay. The subject of gold determination by atomic absorption is discussed in a number of reference books and articles $(8,9,12,13$, $18,30$ to 36$)$.

\section{Optical Spectrography}

Low concentrations of gold may be determined by optical emission spectrography, usually with the lines $242.8 \mathrm{~nm}$ and $267.6 \mathrm{~nm}$. A prior concentration can be made by fire assaying, with the spectrographic measurement carried out on the lead button or the gold-silver bead $(10,14,18,37)$.

\section{X-ray Fluorescence}

Although its application to the determination of gold has been studied by a few workers $(14,18,37$, 38 ), X-ray fluorescence, which is so useful in many fields of metallurgical chemistry, has not become 
established as a routine analytical procedure for the metal. This is disappointing because, as a general rule, elements of high atomic number such as gold are more amenable to determination by X-ray fluorescence than those of low number and, furthermore, the non-destructive nature of the technique could be advantageous in laboratory analyses of many materials for gold. However, gamma-ray fluorescence has found an important application in a recently developed 'Portable Gold Analyzer' for underground reef sampling (39).

\section{Analytical Standards}

Gold analytical standards can be obtained in rod, sheet, wire and sponge form or as chloride or ammonium chloraurate from Johnson, Matthey \& Co., Ltd., of London. All these products are available with an impurity content of less than $5 \mathrm{ppm}$.

Gold is also one of the elements available in bar form of 'five-nines' grade - that is, 99.999 per cent pure or with less than $10 \mathrm{ppm}$ impurity content from Asarco Inc., of New York.

A gold reference standard for atomic absorption, containing $1 \mathrm{mg}$ gold $/ \mathrm{ml}$, is listed in some catalogues of chemical reagents.

\section{Impurities Associated with Gold}

In gold bullion, very small quantities of one or more of the following elements are usually present: arsenic, bismuth, copper, iron, lead, magnesium, manganese, nickel, platinum group metals, silver and zinc.

In jewellery or dental alloys, gold may be accompanied by substantial amounts of one or more of the following metals: copper, nickel, palladium, platinum, silver and zinc. Other elements may be present, especially in dental gold alloys and in jewellery or dental solders.

The list of elements associated with gold in other industrial products is lengthy: aluminium, bismuth, cadmium, chromium, copper, indium, iron, lead, molybdenum, nickel, palladium, platinum, rhodium, silicon, silver, tantalum, tin, titanium, tungsten, vanadium and zinc are some of these.

Appropriate analytical procedures for all these impurities may be found in standard reference books ( 1 , $3,5,25,30)$.

\section{Conclusion}

The determination of gold can be satisfactorily effected by a number of analytical methods. With the current marked increase in the price of gold, it is not unrealistic to anticipate that further research in the analytical chemistry of this ancient metal will soon bring about improvements in the accuracy and rapidity of analytical methods.

\section{References}

1 V.S. Dillon, 'Assay Practice on the Witwatersrand', Transvaal and Orange Free State Chamber of Mines, Johannesburg, 1955

2 'Analysis of Cyanidation Solutions and Gold Precipitate', Imperial Chemical Industries, London, 1963

3 'Scott's Standard Methods of Chemical Analysis', edited by N. H. Furman, 6th edition, Vol. 1, Van Nostrand, Princeton, 1962

4 I. M. Kolthofr and P. J. Elving, "Treatise on Analytical Chemistry', Part 11, Vol. 4, Interscience, New York, 1966

5 R. S. Young, 'Chemical Analysis in Extractive Metallurgy', Charles Griffin, London, 1971

6 R. S. Young, 'Separation Procedures in Inorganic Analysis', Charles Griflin, High Wycombe, 1979

7 D. A. Beardsley, G. B. Briscoe, J. Ruzika and M. Williams, Talanta, 1966, 13, 328-331

8 L. R. P. Butler, J. A. Brink and S. A. Engelbrecht, Trans. Inst. Min. Metall., 1967, 76, C188-C191

9 C. E. Thompson, H. M. Nakagawa and G. H. van Sickle, U.S. Geol. Surv. Prof. Pap., 1968, No. 600B, B130-B132

10 N. Jordanov, St. Mareva, N. Krasnobaeva and N. Nedyalkova, Talanta, 1968, 15, 963-968

11 N. Ichinose, Talanta, 1971, 18, 105-109

12 M. A. Hildon and G. R. Sully, Anal. Chim. Acta, 1971, 54, 245-251

13 B. Strong and R. Murray-Smith, Talanta, 1974, 21, 1253-1258

14 F. E. Beamish, "The Analytical Chemistry of the Noble Metals', Pergamon, Oxford, 1966

15 R. Dybczynski and H. Maleszewska, Analyst, 1969, 94, 527-537

16 J. S. Fritz and W. G. Millen, Talanta, 1971, 18, 323-327

17 D. F. C. Morris and M. Ali Khan, Talanla, 1968, 15, 1301-1305

18 F. E. Beamish and J. C. van Loon, 'Analysis of Noble Metals', Academic Press, New York, 1977

19 A. Chow and F. E. Beamish, Talanta, 1967, 14, 219-231

20 W. W. White and J. R. Zuber, Anal. Chem., 1964, 36, 2363-2364

21 E. E. Bugbee, 'A Textbook of Fire Assaying', Wiley, New York, 1940

22 E. A. Smith, "The Sampling and Assay of the Precious Metals', Charles Griffin, London, 1947

23 R. S. Young, Talanta, 1975, 23, $125-130$

24 R. J. Puddephatt, 'The Chemistry of Gold', Elsevier, New York, 1978

25 E. B. Sandell and H. Onishi, 'Photometric Deternination of Traces of Metals', 4th edition, Wiley, New York, 1978

26 W. B. Holbrook and J. E. Rein, Anal. Chem, 1964, 36 , $2451-2453$

27 I. E. Lichtenstein, Anal. Chem., 1975, 47, 465-468

28 A. W. Titley, Analyst, 1962, 87, 349-355

29 J. Adam and R. Pribil, Talanta, 1971, 18, 405-409

$30 \mathrm{~K}$. C. Thompson and R. J. Reynolds, 'Atomic Absorption, Fluorescence and Flame Emission Spectroscopy', 2nd edition, Charles Griffin, London, 1978

31 T. P. Michailova and V. A. Rezepina, Analyst, 1970, 95, 769-775

32 T. Groenewald, Anal. Ghem., 1969, 41, 1012-1015

33 E. N. Pollock and S. I. Andersen, Anal. Chim. Acta, 1968, 41, $441-446$

34 S. L, Law and T. E. Green, Anal. Chem., 1969, 41, 1008-1012

35 F. W. E. Strelow, E. C. Feast, P. M. Mathews, C. J. C Bothma and C. R. van Zyl, Anal. Chem., 1966, 38, 115-117

36 J. C. van Loon, Z. Anal. Chem., 1969, 246, 122-124

37 F. E. Beamish, C. L. Lewis and J. C. van Loon, Talanta, 1969 16, $1-25$

38 T. E. Green, S. L. Law and W. J. Campbell, Anal. Chem., $1970,42,1749-1753$

39 Chamber of Mines of South Africa, CM Report, 1979, March, 6-7

T. A. Davies, P. J. D. Lloyd, D. A. Roberts and R. Rolle, 7 Inst. Mine Surv. S. Afr., in press 